\title{
A DISSIMULAÇÃO NOS GÊNEROS CÔMICOS
}

\section{THE DISSIMULATION IN COMIC GENDERS}

\author{
Aline Stefânia Zim
}

Professora do Departamento de Arquitetura da Universidade Católica de Brasília - UCB. Doutoranda em Estética pelo PPG FAU da Universidade de Brasília - UnB.

\begin{abstract}
RESUMO
A partir da análise de alguns textos de Heidegger e Nietzsche sobre a verdade, mentira e dissimulação, propõe-se a investigação de três gêneros artísticos literários que utilizam da dissimulação como recurso fundamental: a) a ironia, a qual dissimula a verdade falando o contrário do que se pensa; b) a paródia, que oculta ou nega o sentido interior daquilo que é parodizado, e c) a farsa medieval, que dissimula a realidade pela sua ridicularização.
\end{abstract}

Palavras-chave: Dissimulação; Verdade; Ironia; Paródia; Farsa.

\section{ABSTRACT}

From the analysis of some Heidegger and Nietzsche texts about truth, lies and dissimulation, it is proposed the investigation of three literary artistic genres that use dissimulation as a fundamental resource: a) irony, which conceals the truth by saying the opposite of what think about; B) parody, which conceals or denies the inner sense of what is parodied, and c) medieval farce, which conceals reality by its ridicule.

Keywords: Concealment; Truth; Irony; Parody; Farce.

\section{Introdução}

O conceito de dissimulação em Heidegger (1979) trata da essência da verdade, da não-verdade, do velamento e do desvelamento. Para tanto, o filósofo trabalha em duas direções: da concordância entre enunciação e coisa (p.134), e da afirmação de que a essência da verdade é a liberdade (p. 137).

Na primeira hipótese, a verdade é entendida como conformidade, ou seja, como a adequação da coisa com o conhecimento. Cabe aqui o conceito de "concordância" pelo filósofo, onde "uma enunciação é verdadeira quando aquilo que ela designa e exprime está conforme com a coisa a qual ela se pronuncia". Ser verdadeiro aqui é estar de acordo pela concordância entre uma coisa e o que dela se presume, e de outro lado, pela conformidade entre o que é significado pela enunciação e pela coisa (HEIDEGGER, 1979, p. 133).

A verdade, nesse paradigma, se limita ao conhecimento prévio. Se os objetos se conformam com o nosso conhecimento (Kant), eles dependem da ideia pré- concebida que se tem sobre as coisas. A concordância entre as coisas ou entes, nesse contexto kantiano, é na verdade a concordância entre os entes com a ideia, ou melhor, da criatura com o criador, dentro da ordem da criação divina. A lei da criação e essa dimensão teológica da concordância pode ser substituída pela ordem do mundo na dimensão da razão universal. "A verdade da coisa significa sempre o acordo da coisa dada com seu conceito essencial, tal como o "espírito" (a razão) o concebe." (p. 134) A não-verdade seria a não concordância da enunciação com a coisa, ou do ente com sua essência. A enunciação, sendo de natureza diferente da coisa, adequa-se à coisa, concorda com a coisa.

O conceito de verdade proposto aqui é mais amplo, incluindo a sua antítese, a não-verdade, assim como o autêntico e o não autêntico, o verdadeiro e o falso, o oculto e o aparente. O que é dissimulado e a própria dissimulação são tratados como coisas reais. O ouro falso é tão real quanto o verdadeiro, mas sua aparência não condiz com sua realidade, porque ela dissimula sua verdadeira natureza que é não ser ouro. 
Por outro lado, entender a essência da verdade como sendo a liberdade humana é deslocar a verdade para a subjetividade e estar à sua disposição. A falsidade, a hipocrisia, a mentira, a simulação e a dissimulação são modos de não-verdade, e a não-verdade se coloca como contrária à verdade, revelando assim a origem humana da não-verdade e, por oposição, a origem.

Heidegger apresenta e refuta em seu texto a tese de que a essência da verdade está na liberdade, na direção de que essa relação, entre a verdade e a liberdade, leva ao problema fundamental da essência humana. A afirmação de que "a essência da verdade se desvelou como liberdade" (p. 140) fornece categorias fundamentais para entender o jogo de velamento e desvelamento.

Na liberdade do ser acontece a dissimulação do ente em sua totalidade, ou seja, o velamento. A dissimulação é o velamento, portanto, que recusa o desvelamento, ou seja, a verdade. A não-verdade original - o velamento do ente - é mais antiga que o desvelamento ou que qualquer revelação do ente. A não-essência original da verdade é o mistério - a dissimulação do que está velado - e o homem estaria dominado por ele, a presença do mistério esquecido. Graças àquilo que lhe é acessível na vida corrente, a humanidade insiste em assegurar-se através de si mesma. “O homem se engana nas medidas tanto mais quanto mais exclusivamente toma a si mesmo, enquanto sujeito, como medida para todos os entes" (p. 142). Mesmo na existência insistente reina o mistério, mas como essência esquecida, e assim ornada "inessencial" da verdade (p.142).

Mais adiante no texto, Heidegger afirma que a errância participa da constituição íntima do ser à qual o homem historial está abandonado. A errância é o espaço de jogo deste vaivém de esquecimento e engano. A dissimulação velada se afirma no desvelamento do ente particular que, como esquecimento da dissimulação, constitui a errância. Se a essência da verdade está fundamentada na dissimulação e na errância, e não reduzida à conformidade ou à liberdade do deixar-ser, o seu fundamento não encontra respostas universais e sim particulares. O único dissimulado é o ente em sua totalidade. Aqui Heidegger propõe a aletheia como uma clareira, sobre a qual o ser possui o velar iluminador, este aparecendo à luz da retração que dissimula (p. 145).

No texto de Nietzsche sobre a verdade e a mentira no sentido extramoral (1873, p. 1 in NIETZSCHE, 1983, pp. 43-45), a origem da verdade e da mentira, na concepção tradicional ocidental de crença, está disposta a partir do critério da utilidade dessa verdade. O homem do rebanho chama de verdade o que o mantém ali e chama de mentira o que o ameaça ou exclui do rebanho. A verdade, portanto, é a verdade do rebanho.
O homem é um animal iludido que entra em desespero quando toma a consciência da sua existência efêmera; o intelecto, por sua vez, é um órgão fingidor que oculta o fundo trágico da existência, ilude e dissimula a realidade, forja imagens luminosas para lançar um véu sobre esse fundo trágico. Obstinado pelo seu próprio intelecto, o homem é o mestre da dissimulação, que tenta captar o mundo por metáforas e conceitos. O intelecto, enquanto meio de conservação do indivíduo, desenvolve o essencial de suas forças na dissimulação. Nos animais mais fracos este é o meio de conservação, pois munidos de chifres ou das poderosas mandíbulas enfrenta-se uma luta pela existência, por exemplo. Essa dissimulação acontece em razão da própria sobrevivência.

Mas é no homem que esta dissimulação atinge o seu ponto culminante pelos recursos da ilusão, da lisonja, da mentira, do engano, da calúnia e da ostentação. A vaidade do homem o faz desviar a vida por um brilho emprestado, o faz usar máscaras e brincar de comediante diante dos outros e de si mesmo. O amor à vaidade é a regra e o modelo, a tal ponto, que chega a ser inconcebível que apareça um instinto de verdade e de honestidade puros. Por isso consideramos a realidade e a aparência não como antíteses, e sim suas gradações, que não correspondem à essência. Não nos protegeríamos se houvesse algo de dissimulador, enganador ou palhaço na essência das coisas (NIETZSCHE, 1983, pp. 43-50). O sujeito não pode demonstrar a si mesmo ou enganar a si mesmo, já que ele não está do lado de fora:

\begin{abstract}
Mas o que sabe o homem, na verdade, de si mesmo? E ainda, seria ele sequer capaz de se perceber a si próprio, totalmente de boa-fé, como se estivesse exposto numa vitrine iluminada? A natureza não Ihe dissimula a maior parte das coisas, mesmo no que concerne a seu próprio corpo, a fim de mantê-lo prisioneiro de uma consciência soberba e enganadora, afastado das tortuosidades dos intestinos, afastado do curso precipitado do sangue nas veias e do complexo jogo de vibrações das fibras?

(NIETZSCHE, 2008, p. 553).
\end{abstract}

O homem utiliza sua inteligência na maioria das vezes com fins de dissimulação, dentro de todas as convenções estabelecidas da linguagem. Nessa lógica do fundamento dissimulador enganador das coisas e de sua vontade fundante, teríamos que dali fazer parte, para que pudéssemos "não sermos enganados". Mas para conseguir viver em sociedade, no seu rebanho, numa espécie de tratado de paz, há um esforço em direção ao instinto de verdade e às leis da verdade. Ocorre então a oposição entre verdade e mentira. 0 mentiroso faz parecer real o que é irreal; mede as condições estabelecidas e opera substituições. A sociedade pune a mentira e assim o indivíduo teme a punição ou as consequências resultantes, não propriamente a mentira. 
O homem é indiferente diante do conhecimento puro da verdade, mas pode ser hostil com as verdades prejudiciais e destrutivas. Por outro lado, pode tomar uma ilusão vazia de fundamentos como verdade, se assim o quiser. Os sistemas de classificações, por exemplo, que definem a palavra l'arbre como masculina e planta como feminina nos mostram que estamos afastados das certezas e dogmas e íntimos de delimitações parciais e arbitrárias das diferentes línguas e suas palavras diversas, as quais nunca alcançam a verdade. Nietzsche refuta a ideia de que a verdade teria sido o fator determinante na gênese da linguagem. As línguas designariam somente uma relação entre os povos e se utilizariam das metáforas mais audaciosas, ou seja, da dissimulação da verdade (NIETZSCHE, 1983, pp. 43-50).

O homem acredita possuir o saber sobre as coisas propriamente, mas conhecidas apenas suas metáforas, som e imagem, as quais não correspondem às entidades originais. A linguagem não provém da essência das coisas, tampouco os conceitos. Os conceitos surgem da postulação da identidade do não-idêntico.

O conceito, sendo genérico, ignora o particular e prioriza uma forma primordial fundamentada nela mesma. Essa forma primordial não é a causa do particular, muito menos o conceito. Mesmo assim postulamos características e ações idênticas deixando de lado o que as torna diferentes. A omissão do particular e do real nos dá o conceito e a forma, diferente da natureza que desconhece formas, conceitos e gêneros. "O que é, portanto, a verdade? Uma multidão móvel de metáforas, metonímias e antropomorfismo" realçadas pela poesia e pela retórica e, depois de algum tempo, canonizadas. "As verdades são ilusões das quais se esqueceu que são, metáforas gastas que perderam a sua força sensível", e são conduzidas geralmente por um impulso moral que orienta o sentimento para a essas verdades. O mentiroso é excluído por não usar desse impulso moral que dá utilidade à verdade (NIETZSCHE, 1983, pp. 43-50).

O que eleva o homem racional acima do animal é o seu afastamento diante dos impulsos e das metáforas intuitivas, ou seja, a dissolução das imagens em conceitos. O mundo intuitivo das primeiras impressões, nesse contexto apontado por Nietzsche, é submetido a um outro mundo lógico regulador e imperativo. Chama-se verdade o fato de se usar cada conceito com sua designação correta dentro do sistema. As catedrais conceituais infinitamente complicadas sobre fundações movediças fariam do homem um poderoso "gênio da arquitetura". Aqui o filósofo ressalta a sua postura irônica diante dos sistemas de conhecimento racionais dominantes e contrapõe: "para encontrar um ponto de apoio em tais fundações, precisa-

${ }^{1}$ https://pt.wikipedia.org/wiki/Ironia se de uma construção semelhante às teias de aranha, tão fina que possa seguir a corrente da onda que a empurra, tão resistente que não se deixe despedaçar à mercê dos ventos." (NIETZSCHE, 1983, pp. 43-50).

As definições científicas, segundo o filósofo, são em sua maioria antropomórficas e antropomorfizadas e são limitadas enquanto verdades, como um eco deformado de uma voz primordial. Entre duas naturezas distintas o sujeito e o objeto - não há qualquer laço de causalidade. Há sim uma relação estética, ou seja, no sentido dado. Não se dispõe do critério da percepção justa, ou seja, da expressão adequada de um objeto num sujeito. O que se dispõe é de ideias compostas por metáforas em processo de esclerose e de cristalização. Sobre a percepção e os fenômenos,

Nenhum caminho regular leva dessas intuições ao país dos esquemas fantasmagóricos, ao país das abstrações: para aquelas, a palavra ainda não foi forjada; o homem fica mudo quando as về, ou só fala por metáforas proibidas e por encadeamentos conceituais até então inauditos, para responder de maneira criativa, pelo menos pelo escárnio e pela destruição das velhas barreiras conceituais, a impressão que dá o poder da intuição atual. (NIETZSCHE, 1983, pp. 43-50).

A partir das categorias de verdade, mentira e dissimulação, Nietzsche propõe a tese da relatividade do conhecimento humano. A ciência, segundo ele, trabalha em grandes sistemas de conceitos que são eles próprios o cemitério das intuições. Os instintos não estão submetidos à verdade, apenas estão disciplinados de acordo com os conceitos atribuídos a eles. O homem "acordado" paradoxalmente estaria envolvido num mundo mais próximo do onírico, "tão diverso, irregular, vão, incoerente, uma forma sempre nova e cheia de encanto". (NIETZSCHE, 1983, pp. 43-50).

A partir dessa breve análise dos textos de Heidegger e Nietzsche sobre a verdade, mentira e dissimulação, propõe-se a investigação de três gêneros artísticos literários que utilizam da dissimulação como recurso fundamental: a ironia, a paródia e a farsa medieval.

\section{Ironia}

A ironia tem seu conceito historicamente modificado desde a Antiguidade, atribuída primeiramente à Sócrates. A ironia (do grego antigo eipwveía, trad. eironēia, 'dissimulação') é uma forma de expressão literária ou uma figura de retórica ${ }^{1}$. O conceito mais conhecido vem da retórica, onde ironia é dizer o contrário do que se pensa. Geralmente, o tom irônico consiste na seriedade ao falar algo que não foi pensado seriamente, ou seja, não há seriedade verdadeira. Ou ao contrário, dizer em tom de brincadeira algo que é sério. 
Alguns autores supõem que a ironia é uma forma de mentira; outros defendem, desde a Antiguidade, que a ironia é um recurso retórico alto, pretensioso de nobreza e elevação, justamente por confundir ou velar o discurso. A pretensão do discurso irônico seria comparável a um enigma não decifrado totalmente ou decifrado por poucos: somente os que alcançam sua posição elevada, longe da posição das pessoas comuns. Nesse sentido, o sujeito irônico aprisiona o outro pela ignorância, pois tenta mistificar o mundo a partir da ironia. Ao contrário da dúvida, que mantém o seu objeto na solução, a ironia é como um jogo, um enigma, que guarda o foco nele mesmo, a ponto de distanciar o sujeito da realidade por ser a ironia mais interessante ou intrigante. Assim como num show de ilusionismo, o público desejaria, pelo jogo da ironia, ser persuadido.

Um dos conceitos mais importantes na visão de Hegel sobre a ironia é o da negatividade irônica. Para Kierkeggard (2013), em O conceito de ironia, "dizer o contrário do que se pensa" significa que o fenômeno não é essência, mas o contrário da essência. Entendendo que o pensamento é a essência, ou seja, o que eu penso, a palavra seria o fenômeno. Segundo o mesmo autor, quando o enunciado feito pelo interlocutor corresponde à opinião deste, tem-se um sujeito positivamente livre. Quando o enunciado não corresponde à opinião, o sujeito está livre em relação aos outros e a ele mesmo, ou seja, está negativamente livre (KIERKEGGARD, 2013, p. 247).

Kierkeggard (2013:262), ao citar Hegel sobre a negatividade irônica infinita e absoluta, explica que "ela é negatividade, pois apenas nega; ela é infinita, pois não nega este ou aquele fenômeno; ela é absoluta, pois aquilo, por força de que ela nega, é um mais alto, que, contudo, não é". Segundo esse autor, a ironia é uma determinação da subjetividade de um indivíduo que está negativamente livre, flutuante, suspenso, embriagado na infinitude de possibilidades. Esse vislumbre de possibilidades, segundo o autor, está relacionado ao entusiasmo na própria destruição da realidade pela realidade mesma - e não à criação de algo novo - o que faz o sujeito desenvolver uma destruição interna, dentro de uma possível dialética entre criação e destruição.

Há dois movimentos históricos, nesse sentido, o do profeta e do herói trágico. O indivíduo profético vislumbra o novo ao pressentir o futuro. Perdido para a sua realidade porque já não vive mais o presente, não se opõe a sua época, ou se opõe de forma pacífica. Já o herói trágico opõe-se à realidade e luta para que o passado seja destruído, ou diminuído a tal ponto que se instaure algo novo. Esse seria o sujeito irônico que sabe que o presente não corresponde à ideia (KIERKEGGARD, 2013, p. 262).
Para Hegel, é na condição de autodestruição que consiste a universal ironia do mundo. É irônico, portanto, o sacrifício de uma vítima para que o mundo se desenvolva, ou a promessa de salvação a partir do cumprimento dos Dez Mandamentos, para uma sociedade que não poderia cumpri-los (KIERKEGGARD, 2013, p. 263). Resta perguntar se a realidade destruída é a destruição da sua própria dissimulação e uma possiblidade de desvelamento da verdade.

\section{Paródia}

Primeiramente, analisemos o conceito de comédia, cômico e comicidade. Aristóteles, ao classificar os gêneros literários na Poética, trata da tragédia e da epopeia como gêneros superiores. A comédia, segundo o texto, é imitação de caracteres mais inferiores, ainda que não completamente viciosos; mais propriamente o ridículo constitui parte do disforme. A máscara do riso, embora disforme e distorcida, não gera dor. As etapas de desenvolvimento relativas à tragédia, bem como seus autores, têm sido lembradas por nós, ao passo que a história inicial da comédia mergulhou no esquecimento, porque não despertou nenhum sério interesse (ARISTÓTELES, Poética, 2011, p. 47).

O conceito de paródia, do grego para-ode, significa uma ode que perverte o sentido de outra ode. A origem, que é de ordem musical, já que uma ode era um poema para ser cantado, aponta para a ideia de uma canção que era cantada ao lado da outra, um canto paralelo ou como um contracanto. Apesar de ser institucionalizado a partir do século XVII, o termo paródia é citado por Aristóteles numa situação de inversão, onde Hegemon de Thaso (séc. 5 a.C.) usa o estilo épico para representar os homens inferiores em relação ao seu cotidiano, apontando para uma degradação do gênero da epopeia. Nesse contexto, a tragédia e a epopeia eram gêneros maiores e nobres, enquanto a comédia era o espaço da representação popular.

A paródia consiste, para alguns, num exagero cômico, que revela a comicidade. Mas nem sempre ela contém um exagero. O exagero é próprio da caricatura e não da paródia. A paródia consiste na imitação das características exteriores de um fenômeno qualquer de vida, das maneiras de uma pessoa, dos procedimentos artísticos, de modo a ocultar ou negar o sentido interior daquilo que é submetido à parodização. É possível parodiar tudo: os movimentos e as ações de uma pessoa, seus gestos, o andar, a mímica, a fala, os hábitos de sua profissão e o jargão profissional; é possível parodiar o que se é criado por uma pessoa no campo do mundo material. 
A paródia tende a demonstrar que por trás das formas exteriores de uma manifestação espiritual não há nada, ou então que por trás delas existe o vazio. Por exemplo, o palhaço imitando a amazona, onde a sua paródia revela não o vazio do que é parodiado, mas a ausência das características positivas que imita; ou o aluno posto de castigo que imita o professor a dar aula.

O aparecimento de uma paródia em literatura demonstra que a corrente literária parodiada começa a ser superada. Tchekhov, nesse sentido, parodia o estilo romântico de Victor Hugo, o fantástico de Júlio Verne, os romances policiais, ridicularizando os estilos do ponto de vista de uma nova tendência, o romance realista. A paródia é um dos instrumentos mais poderosos de sátira social e se manifesta no folclore, por exemplo. A paródia é cômica quando revela a fragilidade interior do que é parodiado, geralmente dirigidas contra fenômenos de caráter sócio-políticos (PROPP, 1992, pp. 86-89).

Segundo Sant'Anna, após ter se manifestado na Grécia, Roma e Idade Média, a paródia é retomada enquanto gênero na modernidade, com o Futurismo (1909) e o Dadaísmo (1916). Essa linguagem, que se dobra sobre si mesma num jogo de espelhos, é retomada no texto literário como efeito metalinguístico (a linguagem que fala de outra linguagem), sendo possível distinguir não apenas uma paródia de textos alheios (intertextualidade) como uma paródia dos próprios textos (intratextualidade) (SANT'ANNA, 2000, p. 07).

O autor faz uma comparação entre os conceitos de paródia, paráfrase, estilização e apropriação. Primeiramente, ele propõe a antítese entre paródia e paráfrase, diferente das comparações originais de Bakhtin e Tinianov, entendendo a paráfrase como a afirmação e continuidade da ideia dominante, e a paródia a sua descontinuidade, ou seja, o movimento da contra-ideologia. Dentre outras comparações, sugere a paródia a partir da intertextualidade das diferenças, enquanto a paráfrase, da intertextualidade das semelhanças. Enquanto a paráfrase é um discurso em repouso, a estilização é a movimentação do discurso e a paródia é o discurso em progresso. $\mathrm{Na}$ paráfrase o efeito de condensação e o reforço, enquanto na paródia, o deslocamento e a deformação.

A paródia busca, num caráter contestador, a fala recalcada do outro, aquela voz social ou individual que é preciso desentranhar para que se conheça o outro lado da verdade. Nesse contexto, a paródia assume uma atitude contra-ideológica, onde a ideologia tende a repetir suas afirmações tautologicamente diante de um espelho; denuncia o próprio jogo, colocando as coisas fora do seu lugar. A paródia produz um choque de interpretações, uma tomada de consciência crítica e, posteriormente, um gesto autoral (SANT'ANNA, 2000, pp. 13-29).

\section{Farsa medieval}

A farsa medieval é um gênero popular oriundo do teatro religioso medieval e atinge seu apogeu junto aos mistérios, principalmente na Alta Idade Média. A palavra farsa e seus derivados vem da palavra francesa farce, original do latim farcire, que significa rechear, introduzir. 0 verbo farcir, em francês, é usado na culinária para toda ação de rechear. De modo sutil, supõe-se que a farsa, enquanto gênero teatral na Idade Média, era uma comédia que se 'introduzia', por interpolação, no Mistério, que era o auto teatral religioso.

Segundo Charles Mazouer (1998), desde o século XIII, a farsa é usada no sentido de trapacear e no século XV designa uma pequena peça cômica de episódios bufonescos inserida no contexto dos mistérios. Ali o sentido está mais próximo da ação de pregar uma peça ou um golpe a alguém. Já Rey-Flaud (1994) associa o substantivo farsa ao verbo farcer, do francês antigo, que significa enganar, definindo a farsa como uma peça dramática curta, essencialmente cômica, de certa simplicidade, que se utiliza da trapaça como tema ou estrutura de base.

A farsa se origina por sua natureza cômica inserida num contexto inicial dramático para servir de intermédio criativo. Não por acaso, o teatro do riso e da contestação era apresentado no mesmo período que o teatro de edificação religiosa. Essa manifestação artística era bastante complexa e variada e pouco seguia regras ou limites de um gênero. De qualquer modo, o teatro medieval não segue os critérios gregos do cômico e do trágico, onde há uma distinção clara. Esse gênero faz uma caricatura da realidade cotidiana e da selvageria, assim questionando os valores da época. Era no teatro que o povo, após assistir devotamente aos mistérios edificantes, encontrava o repouso, o prazer da zombaria e da crítica e certa liberação. Os temas mais comuns são emprestados das fábulas populares medievais, dos provérbios e das narrativas de tradição oral.

A estrutura de base da farsa é o próprio jogo de enganar ou trapacear alguém, independente da complexidade da ação. A trapaça é o principal mecanismo da ação, por exemplo, na farsa $O$ cego e o menino, que aparece no século XIII, onde os dois personagens usam da trapaça como uma espécie de acerto de contas (MACHADO, 2009, p. 124). 
Outro tema recorrente desse gênero é a inversão da autoridade: o direito de comando, que ora pertence ao patrão, ora ao criado, ou transita entre o marido e a mulher. A farsa apresentaria, por exemplo, a mulher trapaceando ou espancando o marido usando de recursos cômicos.

A obscenidade e hipocrisia religiosa eram temas também recorrentes nas farsas medievais e se revelavam na forma de denúncia sobre os abusos cometidos, sem, no entanto, questionar a natureza das coisas. Por exemplo, a luxúria de alguns padres era denunciada pelo cômico, fazendo o público rir. Nesse contexto, o jogo cênico entre gestos e linguagem eram baseados nos códigos da praça pública, explorando um vocabulário popular que usa largamente da comicidade, do equívoco e do duplo sentido.

Nesse sentido, alguns autores não reconhecem a função moral desse gênero, enquanto outros acreditam que há na farsa uma função social de se fortalecer os ideias éticos e por isso o teatro usa de lições morais e ataques satíricos. O riso, segundo estes, só é possível dentro de um contexto cultural de identificação cujos elementos estejam em conflito. Segundo Alan Knight (1981), em A farsa e a moralidade, nesse contexto cria-se um mundo imaginário onde os conflitos da sociedade são colocados em relevo.

A dissimulação da verdade pelo cômico medieval é explorado por Bakhtin no conceito da carnavalização na obra de François Rabelais, a partir dos estudos sobre a cultura popular na Idade Média. Nesse contexto, a praça pública, palco dos teatros medievais, das festas e da farsa, era o espaço legalizado da linguagem popular, o ponto de convergência de tudo que não era oficial. Num ambiente de liberdade, franqueza e familiaridade, o povo tinha sempre a última palavra. (BAKHTIN, 1999, p. 132).

\section{Sobre a natureza da comédia}

De Aristóteles até hoje os estudiosos de estética repetem que o disforme é cômico e o oposto do sublime, mas não explicam e não definem que tipo de deformidade é risível e qual não é. Nem toda deformidade é cômica, mas as diferenças culturais, por exemplo, são propícias à comicidade (PROPP, 1992, p. 59).

Jean Paul (1991), afirma que o humor, enquanto destruição do sublime, não elimina o indivíduo, mas o finito em contraste com a ideia. Diferente das ideias do cômico vulgar, não há uma loucura individual e sim um a estupidez e a loucura no mundo. O humor rebaixa a grandeza e eleva a pequenez, mas de modo distinto da paródia e da ironia. Ele o faz colocando o grande ao lado do pequeno, ao mesmo tempo que o pequeno ao lado do grande, reduzindo ambos a nada, pois, diante do infinito, tudo é igual e tudo é nada (p. 67).

A afirmação de Jean Paul é fundamental para se entender o cômico na sua dimensão contraditória. A natureza da comicidade não é revelada pela contraposição do cômico ao trágico e ao sublime, e sim pelas suas contradições internas. É preciso compreender o cômico enquanto tal, ou seja, questionar em quais condições os defeitos das pessoas são cômicos, ridículos, ou quando os objetos reais à nossa volta não correspondem aos conceitos e representações que deles fazemos. O cômico se baseia na contradição entre forma e conteúdo. Deve-se analisar os casos concretos e não propor soluções apriorísticas, para se decidir se há algum tipo de contradição na base do cômico.

Em geral tem-se uma atitude negativa quanto ao cômico, independente de sua ordem. Há dois aspectos do cômico: o de ordem superior e o de ordem inferior; o cômico alto e o baixo. Alguns autores entendem o cômico baixo ou inferior - tudo que está ligado ao corpo e suas tendências ou necessidades naturais (Volkelt). Outros remetem aos tipos de farsas, de palhaçadas, espetáculos circenses (Leacock, livro de contos humorísticos). Apesar de típicos temas da literatura vulgar e popular, a literatura erudita também se apropria do cômico baixo. Nas obras elevadas, permeiam os elementos de farsa e do cômico-baixo (Gogol, Molière, etc.), como linguagem pejorativa e xingamentos.

A princípio, o aspecto refinado da comicidade se daria para as pessoas cultas, os aristocratas de espírito e de origem; o aspecto vulgar, ou cômico-baixo, seria reservado à plebe, ao vulgo, à multidão, adequado ao teatro popular (Beyer), onde os conceitos de decência, de decoro e de comportamento civilizado possuem limites mais amplos. Púchkin afirma que o drama surgiu na praça e tornou-se um divertimento popular. O verdadeiro reino da farsa são as representações das feiras. A farsa é incorporada em grandes escritores como Rabelais e Cervantes. As "brincadeiras de mau gosto, as farsas triviais, as anedotas equívocas, de variedades vazias e de burlas idiotas" são encontradas em todos os setores da produção literária. Assim fica muito difícil dividir o cômico em elevado e vulgar, mas deve-se considerar os aspectos morais e artísticos nas formas de comicidade (PROPP, 1992, pp. 20-25).

A teoria da carnavalização em Bahktin, por exemplo, é uma forma de estudar os textos literários e mesmo a cultura de um povo, procurando os efeitos cômicos e parodísticos que mostram como a comédia pode revelar 
alguns traços do inconsciente social. A partir do estudo das máscaras, do grotesco, do riso, das antíteses entre vida e morte, religião e festa, violência e orgia, inverno e primavera, carnaval e quaresma, pode-se estudar a dialética da própria vida (SANT'ANNA, 2000, p. 94). O conceito de paródia foi estrategicamente importante para o entendimento da literatura como sistema, pois mostra a presença de um subsistema dentro de outro subsistema como negação afirmadora (KOTHE, 1981, p. 133).

Segundo Kothe (1981), a paródia é um culto às avessas ( $p$. 139), que procura liquidar pelo ridículo a postura do texto parodiado, um ataque da dominante de um sistema contra um elemento dominado, como resposta à existência institucionalizada e sacralizadora de um texto.

\section{A ironia como um recurso de elevação e de rebaixamento}

As ideias e doutrinas de Friedrich Schlegel, segundo Hegel, deram origem às várias formas de ironia. Quando esses princípios são aplicados à obra de arte, tem-se a ironia do eu absoluto e abstrato, a partir da filosofia de Fichte. Tal filosofia confere uma soberania à subjetividade, onde tudo pode ser criado e destruído pelo sujeito. Para Hegel, o artista, que deve viver como artista e dar à sua vida uma forma artística, tem a sua verdade pela experiência, do poder e do arbítrio, configurando um formalismo do eu. A virtuosidade de uma vida artisticamente irônica é chamada de genialidade divina, em que o artista olha os outros do alto, achando-os limitados, presos ao direito e à moral. Esse artista é o criador e destruidor liberto que vê a realidade como mesquinha e vã, isolando-se na sua própria insatisfação e tédio.

\begin{abstract}
A ironia, sendo o recurso máximo da individualidade genial, consiste na autodestruição de tudo o que é nobre, grande e perfeito, de modo que a arte fica reduzida, até em suas produções objetivas, à representação da subjetividade absoluta, visto que tudo quanto para o homem tem valor e dignidade se revela inexistente após a sua autodestruição. Razão suficiente para que não se tome a sério não só a justiça, a moral e a verdade, mas também o sublime... não passam de ironia de si próprios.

(HEGEL, 2009, p. 86).
\end{abstract}

Percebe-se aqui uma visão da ironia como rebaixamento moral, ou mesmo o rebaixamento do que está sendo ironizado, ou seja, o objeto ironizado é superior à ironia em si.

A ironia se aproxima do cômico, mas segundo Hegel há diferenças essenciais. Enquanto o cômico limita-se a demolir o que é desprovido de valor em si, por exemplo um fenômeno falso ou contraditório, uma extravagância, que não resistiria à crítica, o irônico repudia e renega todos os valores concretos existentes no indivíduo, renegados a partir dele mesmo. Segundo o mesmo autor, o caráter irônico é mesquinho e desprezível, revelando fraqueza e inferioridade moral (HEGEL, 2009, p. 87).

A Igreja Católica na Idade Média parece ter usado recursos da ironia e da paródia. Durante a Festa do Burro, a Festa dos Foliões ou nas Brincadeiras Pascais, por exemplo, ela se rebaixa permitindo ser parodiada pelo povo. Mas aqui há o recurso da ironia, pois ao rebaixar-se, ela toma a si mesmo como irônica, elevandose acima de sua realidade absoluta (KIERKEGGARD, 2013, p. 254). Nesse caso, a ironia é um recurso de elevação a partir da paródia, por trazer um discurso indireto e incógnito, ou seja, difícil de ser codificado.

A consciência de que há recursos da dissimulação em determinado gênero, texto ou obra é fundamental para a percepção da sua natureza e do seu contexto histórico. Ao considerar a realidade como um conjunto de metáforas cristalizadas e esclerosadas que mais dissimulam a verdade - velam - do que a desvelam, propõe-se aqui a hipótese de que os recursos artísticos, ao usarem da dissimulação da verdade, fazem da arte a dissimulação da dissimulação, ou seja, a negação da negação. Resta saber se a negação da não-verdade pode apontar desdobramentos para a busca da essência da verdade.

\section{REFERÊNCIAS BIBLIOGRÁFICAS}

\section{ARISTÓTELES. Poética. Trad. Edson Bini. São Paulo: EDIPRO, 2011.}

BAKHTIN, M. M. Problemas da poética de Dostoiévski. Trad. Paulo Bezerra. Rio de Janeiro: Forense Universitária, 2015.

A cultura popular na Idade Média e no

Renascimento: o contexto de François Rabelais. Trad. Yara Frateschi Vieira. São Paulo: Hucitec, 2013.

BAUDELAIRE, Charles. Pequenos Poemas em Prosa. Trad. Gilson Maurity dos Santos. São Paulo: Record, 2006.

HEIDEGGER, Martin. Conferências e escritos filosóficos. Trad. e notas Ernildo Stein. São Paulo: Abril Cultural, 1979.

Ser e tempo. Tradução, organização, notas Fausto Castilho. Campinas, SP: Editora da Unicamp; Petrópolis, RJ: Editora Vozes, 2012.

HEGEL, G. W. F. Curso de Estética. O Belo na Arte. Trad. Álvaro Ribeiro Orlando Vitorino. São Paulo: Martins Fontes, 2009. 
KIERKEGAARD, Soren A. O Conceito de Ironia. Constantemente referido a Sócrates. Trad. Álvaro Luiz Montenegro Valls. Rio de Janeiro: Editore Vozes, 2013.

KNIGHT, Alan. La farce et la moralité: Deux genres distincts in Le théâtre au Moyen Âge. Actes de la Société Internationale pour l'étude du théâtre medieval. Alençon: Juillet, 1977. Ouvrage Publio sous la direction de Gari Muller. L'aurore Univers. Montreal-Québec: Ed. Univers inc. 1981.

KOTHE, Flávio R. Ensaios de Semiótica da Cultura. Brasília: Editora UnB, 2011.

Fundamentos da Teoria Literária. Brasília:

Editora UnB, 2002.

Literatura e Sistemas Intersemióticos. São

Paulo: Cortez Autores Associados, 1981.

MACHADO, Irley. A farsa: um gênero medieval. Revista Ouvirouver, n. 5, 2009.

MAZOUER, Charles. Le théâtre français du Moyen Âge. Paris: Ed. Sedes, 1998.

MOISÉS, Massaud. A criação literária: introdução à problemática da literatura. São Paulo: Melhoramentos, 1971.

PROPP, Vladimir. Comicidade e Riso. Trad. Aurora Fornoni Bernardini e Homero Freitas de Andrade. São Paulo: Ática, 1992.
. Morfología del cuento. Trad. del francés.

Díez del Corral. Madrid: Ediciones Akal, 2014.

NIETZSCHE, Friedrich. Obras incompletas. Seleção de textos de Gèrard Lebrun; trad. e notas de Rubens Rodrigues Torres Filho. Coleção Os pensadores. São Paulo: Abril Cultural, 1983.

Obras escolhidas. Trad. Gabriel Valladão Silva, Marcelo Backes, Renato Zwick. Porto Alegre: L\&PM, 2013.

Fragmentos do espólio: primavera de 1884 a outono de 1885. Seleção, tradução e prefácio Flávio R. Kothe. Brasília: Editora Universidade de Brasília, 2008.

REIS, Carlos; LOPES, Ana Cristina M. Dicionário de Narratologia. Portugal: Gráfica Coimbra, 1987.

REY-FLAUD, Bernadette. La farce ou la machine à rire théorie d'un genre dramatique 1450-1550. Genève: Librairie Droz, 1984.

RICHTER, Jean Paul Fr. Introducción a la Estetica. Trad. Julián de Vargas. Editorial Verbum: Madrid, 1991.

SANT'ANNA, Affonso Romano de. Paródia, paráfrase e CIA. São Paulo: Ática, 2000.

TODOROV, Tzvetan. Teoria da literatura: textos dos formalistas russos. Trad. Roberto Leal Ferreira. São Paulo: Editora Unesp, 2013. 